WellBeing International

WBI Studies Repository

2010

\title{
A Critical Review of Electrical Water-Bath Stun Systems for Poultry Slaughter and Recent Developments in Alternative Technologies
}

Sara J. Shields

A. B. M. Raj

University of Bristol

Follow this and additional works at: https://www.wellbeingintlstudiesrepository.org/acwp_faafp

Part of the Agribusiness Commons, Animal Studies Commons, and the Operations and Supply Chain Management Commons

\section{Recommended Citation}

Shields, S. J., \& Raj, A. B. M. (2010). A critical review of electrical water-bath stun systems for poultry slaughter and recent developments in alternative technologies. Journal of Applied Animal Welfare Science, 13(4), 281-299.

This material is brought to you for free and open access by WellBeing International. It has been accepted for inclusion by an authorized administrator of the WBI Studies Repository. For more information, please contact wbisr-info@wellbeingintl.org.

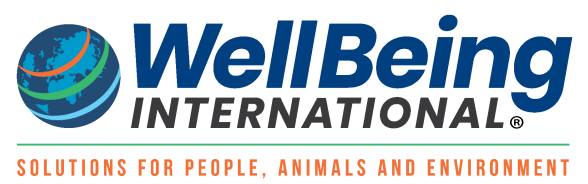




\title{
A Critical Review of Electrical Water-Bath Stun Systems for Poultry Slaughter and Recent Developments in Alternative Technologies
}

Sara J. Shields

Shields Consulting, Lincoln, Nebraska

\author{
A.B.M. Raj \\ Department of Clinical Veterinary Science, University of Bristol, Langford, United Kingdom
}

\section{CITATION}

Shields, S. J., \& Raj, A. B. M. (2010). A critical review of electrical water-bath stun systems for poultry slaughter and recent developments in alternative technologies. Journal of Applied Animal Welfare Science, 13(4), 281-299.

\begin{abstract}
Prior to slaughter, most farmed birds move through a constant-voltage, multiple-bird, electrical water-bath stun system. Using this system subjects live birds to stressful and painful shackling, and the potential exists for them to receive prestun electric shocks and induction of seizures while still conscious. The existing electrical water-bath stunner settings, particularly those used in U.S. slaughter plants, are not necessarily based on sound scientific data that they produce a consistent, immediate stun, and research indicates that they are not effective in all birds. Further, in multiple-bird, electrical water-bath systems, birds may miss the stunner completely. Evidence suggests that some birds may still be alive when they reach the scald vat. For these reasons, electrical water-bath systems are increasingly under scrutiny on nonhuman-animal welfare grounds. Controlled Atmosphere Killing (CAK), a promising alternative technology, uses gas mixtures to render birds unconscious. CAK systems that stun birds while they are still in their transport crates avoid many of the welfare problems associated with the live-hang process and electrical water-bath stunning.
\end{abstract}

In 2008, more than 54 billion farmed birds (Food and Agriculture Organization of the United Nations [FAO], 2008), including nearly 9 billion in the United States (U. S. Department of Agriculture [USDA], 2010), overwhelmingly chickens, were slaughtered. Globally, where slaughter is mechanized, multiplebird, electrical water-bath systems supplied with constant voltages are the most common method of stunning birds prior to slaughter under commercial conditions with high throughput rates. Stunning birds prior to slaughter is practiced to induce unconsciousness and insensibility and to immobilize them for the throat-cutting procedure.

Given the number of birds raised for human consumption globally and the projected rapid increases in per capita consumption, we believe the welfare of farmed birds during slaughter is of significant concern. We believe the poultry industry has an ethical imperative to use the least aversive method that causes the 
minimum of pain and suffering technologically achievable. Many organizations echo our concern. For example, theWorld Organisation for Animal Health (OIE: Office International des Épizooties), which comprises 174 member countries, including the United States, highlighted the importance of basing certain minimum standards of practice on both scientific and ethical grounds in its Resolutions from the 2nd OIE Global Conference on Animal Welfare convened in October 2008 (OIE, 2008a).

Further, the OIE Terrestrial Animal Health Code states, "The use of animals carries with it an ethical responsibility to ensure the welfare of such animals to the greatest extent practicable" (OIE, 2008b). The Animal Agriculture Alliance Coalition, which includes the National Chicken Council, National Turkey Federation, and the U.S. Poultry \& Egg Association as members, asserts, "Farmers, ranchers and veterinarians have an ethical obligation to care for animals raised for food. It is their duty to ensure the safety, health and overall well-being of the animals" (Animal Agriculture Alliance, n.d.), which arguably includes the welfare of nonhuman animals, including poultry, during slaughter.

Corporations commonly assert their commitments to animal welfare, "wellbeing, proper handling, and humane slaughter," pledging, for example, "diligence in leading the industry pursuit of new and improved technology and methods to further enhance animal well-being. This is not only the right thing to do, but is an important moral and ethical obligation we owe to our suppliers, to our customers, to ourselves, and most of all to the animals we depend on for our products and our livelihood" (Tyson, n.d.). Given such strong statements, it is clear that the welfare of birds at slaughter is important to a wide variety of stakeholders. The primary purpose of this review is fourfold:

1. Detail the steps within customary multiple-bird electrical water-bath systems supplied with constant voltages;

2. Outline some of the known/established welfare issues associated with the existing practice;

3. Identify recent research outcomes concerning bird welfare using newer stunning methods, Controlled Atmosphere Stunning (CAS), and Controlled Atmosphere Killing (CAK); and

4. Present the way forward to improving the welfare of farmed birds at slaughter.

\section{ELECTRICAL WATER-BATH STUNNING}

\section{Shackling}

In most of the economically developed countries and where slaughter of poultry is mechanized, farmed birds are transported to slaughter plants where they are first uncrated and then inverted and hung by their legs in metal shackles on an overhead conveyer. The conveyer moves the birds toward the electrified waterbath, where their heads make contact with the electrically charged water. When being hung, individual variation in leg diameter may cause hanging operators to use considerable force to pull thick shanks (legs) into narrow shackles (Gregory \& Bell, 1987; Sparrey \& Kettlewell, 1994).Male birds, who have thicker shanks, may "struggle more violently" than females and they may struggle sooner and longer (Satterlee, Parker, Castille, Cadd, \& Jones, 2000, p. 652). Bruising of the surface of leg and thigh muscles occurs (Lambooij, Pieterse, Hillebrand, \& Dijksterhuis, 1999; Raj, 2004). Nociceptive properties of the skin over the legs of birds provide evidence that shackling is painful (Gentle, 1992; Gentle \& Tilston, 2000). This pain is likely to be worse in birds suffering from diseases or abnormalities of leg joints or leg bones (Danbury, Weeks, Chambers, Waterman-Pearson, \& Kestin, 2000) and those with dislocated joints or bone fractures induced by rough handling during catching, crating, and uncrating. Conflicting bird welfare concerns involve using tight-fitting shackles. Although they may provide good electrical contact between the legs and metal shackles, they are likely to increase the severity of the pain associated with shackling (Sparrey \& Kettlewell, 1994). Hanging upside down is a physiologically abnormal posture for chickens, and handling, inversion, and shackling are "traumatic" and stressful (Bedanova et al., 2007, p. 1069; Debut et al., 2005; Kannan, Heath, Wabeck, \& Mench, 1997; Kannan \& 
Mench, 1996). For these reasons, approximately $90 \%$ of birds flap their wings immediately after shackling, and $66 \%$ flap their wings during any unevenness they experience in the line (Kannan et al., 1997). It is likely that such wing flapping could lead to dislocated joints and/or broken bones, which has not been quantified. However, when birds exhibit wing flapping while shackled, these vigorous movements can lead to hemorrhages of the wing tip (Gregory, Austin, \& Wilkins, 1989).

\section{Prestun Electric Shocks}

It is well documented in the scientific and trade literature that some birds can inadvertently experience painful electric shocks before making contact with the electrified water-bath (European Food Safety Authority [EFSA], 2004a; Gazdziak, 2007; Gregory \& Bell, 1987; Schütt-Abraham, Wormuth, \& Fessel, 1983; Sparrey, Kettlewell, Paice, \& Whetlor, 1993). This can happen when a bird's leading wing makes contact with the water before the head or if wing flapping occurs at the entrance to the stunner. Turkeys are especially prone to prestun shocks (Gregory, 1994; Wooton \& Gregory, 1991) because their wings hang lower than their heads when hung inverted on a shackle. In some slaughter plants, prestun shocks may occur because the ramp at the entrance to the stun-bath is electrically live (Gregory, 1994), although newer entry designs in broiler chicken stunners may prevent overflow of electrically charged water onto the entry ramp (Bilgili, 1999).

\section{Electrical Water-Bath Stunning Efficacy}

The effectiveness of stunning prior to slaughter can be evaluated in a laboratory setting by monitoring electrical activity in the brain, which is recorded using electroencephalograms (EEGs). The electrical activity recorded in the EEGs of sheep and pigs after effective electrical stunning resembles grand mal epilepsy followed by a flat or isoelectric phase, which is a clear indicator of unconsciousness (Gregory \& Wotton, 1987). However, the EEG recordings of chickens following electrical stunning often differ from those of mammals in that the epileptic activity more closely resembles a petit mal seizure (Gregory \& Wotton, 1987), a milder form of epileptic attack in humans (Gregory, 1986). These kinds of seizures are not associated with immediate unconsciousness in humans (Goldie \& Green, 1961; Porter \& Penry, 1973), and this is one of many lines of evidence, further discussed later, to suggest that electrical stunning does not produce immediate unconsciousness in all birds (Boyd, 1994; Gregory, 1986; Gregory \& Wotton, 1987; Raj, 2003). However, because the brain of a chicken responds to electrical stunning differently from the brain of a mammal (Raj, 2003), the subjective experiences of a bird and a mammal may also differ during a petit mal seizure. For both mammals and birds, the occurrence of an epileptiform EEG recording, followed by a quiescent phase, is thought to be the best available evidence of unconsciousness and insensibility and is used in studies of electrical stunning as a measure of the effectiveness of the stun (Raj, 2003; Raj, O'Callaghan, \& Knowles, 2006). Somatosensory evoked potentials (SEPS), electrical signals produced in response to sensory stimuli, are abolished during the manifestation of these two EEG patterns and are a complementary measure of brain function. Short of recording EEG activity and SEPs, monitoring unconsciousness after stunning is not objective or precise; other methods, such as the presence of seizures (convulsions), could lead to inaccurate or erroneous conclusions.

Although the electrical parameters of stun-baths at poultry slaughter plants vary widely, research suggests that commonly used settings in U.S. facilities would not consistently produce an effective stun in all the birds, as discussed in the following paragraphs.

Most of the U.S. broiler chicken industry implements a form of electrical stunning that involves application of a low-current setting with a high frequency, pulsed, direct current (DC; Craig \& Fletcher, 1997; Wilkins, Wotton, Parkman, Kettlewell, \& Griffiths, 1999). Depending on the length of the water-bath and the line speed (Wilkins et al., 1999), the duration of the electric stun usually lasts 10-12 s (Sams, 2001). U.S. stunners may be set at 10-28 volts, delivering 10-45 mA per bird, and the frequency of the current varies between 350 and $500 \mathrm{~Hz}$ (Bilgili, 1999; Gazdziak, 2007; Nunes, 2007). Although precise control of each of these electrical settings relative to the others is important, specific stun settings necessary for an effective and immediate stun are not mandated in the United States. 
There has been very little research into the effectiveness of electrical settings commonly used in stunbaths at U.S. poultry slaughter plants, but recent work demonstrates that the parameters used might not render birds immediately unconscious or may not stun them effectively. Raj, O'Callaghan, and Hughes (2006a, 2006b) have shown that a sine wave alternating current (AC) is more effective at producing EEG recordings indicative of unconsciousness and insensibility than the pulsed DC commonly used in the United States. Moreover, the pulse width of the DC is also an important factor affecting the likelihood that a stun will be effective. Although longer pulse widths (30\% or more of duty cycle) are more likely to produce epileptic EEG recordings, reduced pulse widths are common commercially (Raj et al., 2006a, 2006b).

The typical wave form, pulse width, frequency, and current settings used in the United States are based on achieving good carcass and meat quality rather than on scientific evidence that they effectively produce unconsciousness and insensibility in every bird. There is an inherent conflict between the requirement for effective electrical water-bath stunning and the production of a high-quality carcass and meat free of defects. Although the probability of inducing an effective stun increases as the frequency setting decreases, low-frequency settings cause intense muscle contractions and consequent rupture of small blood vessels in the skin and/or flesh, which causes carcass defects that lead to downgrading (Wilkins et al., 1999). Therefore, higher stunning frequencies $(>300 \mathrm{~Hz})$ have become more prevalent in U.S. slaughter plants (Bilgili, 1999; Gazdziak, 2007) to ensure carcass and meat quality despite the existing potential for an ineffective stun and/or for the bird to recover consciousness following stunning. However, even low-frequency pulsed DC settings are questionable on welfare grounds because although some broiler chickens may experience cardiac arrest at stunning, these birdsmay not show EEGs indicative of effective stunning (Raj et al., 2006a, 2006b). The conflict between bird welfare and meat quality under existing multiple-bird, electrical water-bath stunning systems cannot be corrected and thus necessitates an entirely different approach.

The water-bath may contain up to 20 birds at any one time (Wilkins et al., 1999). In a constant-voltage, multiple-bird stunner, which is standard commercially, the total current equals the sum of the currents flowing though each bird individually (Sparrey et al., 1993). Variation in electrical resistance or impedance in the current pathway caused by natural variability among birds causes differences in the amount of current that individual birds receive as they pass through the water-bath (Bilgili 1999; Kettlewell \& Hallworth, 1990). According to the law of electricity, birds showing high electrical resistance receive currents that are lower than necessary to render them unconscious, whereas birds having low electrical resistance receive more current than necessary to achieve effective stunning. Bird variation can be due to many factors, including body size, body muscle and fat content, and plumage condition. Whether the feathers are wet, dry, or dirty, the depth of immersion and the tightness of shackles are also important factors (Bilgili, 1992; Boyd, 1994; Kettlewell \& Hallworth, 1990). Electrical variables also affect current flow. Mineral content, dirt, and brine concentration all affect the conductivity of the water-bath (Bilgili, 1992; Boyd, 1994). Stunning birds using a multiple-bird, electrified water-bath system is a complex task, and it is extremely difficult, if not impossible, to adequately control the process (Raj, 2004).

Although commercial water-bath stunners generally operate on a constant-voltage basis, it is the current passing through each bird, rather than the voltage, that is important for inducing an effective stun (Sparrey et al., 1993). In constant-voltage stunners, especially those supplied with voltages not sufficient to cause immediate unconsciousness, there is a delay between the start of flow of electricity through the head and the actual stun because the applied voltage gradually breaks down the electrical resistance in the pathway. As a consequence, the current rises from zero to the maximum level-depending on the electrical impedance or resistance in the pathway-and stunning is not immediate. At the low voltage levels used in the United States, this period during which the electrical impedance breaks down could be extremely painful. Constant-current stunners, however, overcome this problem and are potentially able to deliver the maximum current in $0.25 \mathrm{~s}$ (Sparrey et al., 1993).

To overcome the problem of variable electrical impedance in multiple-bird, water-bath stunners, constantcurrent stunners have been developed in the United Kingdom; however, these have not been implemented in slaughter plants. These stunners control current flow through individual birds by electrically isolating each one to ensure that all birds in a multiple-bird, water-bath stunner receive the 
preset minimum current intended to achieve an adequate stun (Sparrey et al., 1993; Wilkins et al., 1999). However, because shackles are only $15 \mathrm{~cm}$ (5.9 in.) apart on the line and adjacent birds are in physical contact with each other and because processing speed can be as high as 220 chickens per minute, there is considerable doubt that it is possible to electrically isolate each bird for long enough to deliver the preset current. As such, commercial application of these systems has been limited (Bilgili, 1999).

It has been suggested that some electrically stunned birds do not receive a current of sufficient magnitude to render them immediately unconscious (Wilkins et al., 1999). Several studies provide data confirming this suggestion. In one study using an average current level that is common in U.S. slaughter plants (44 mA), only $36 \%$ of chickens had EEGs indicative of effective stunning after over $4 \mathrm{~s}$ of exposure (Schütt-Abraham et al., 1983). In another experiment using a $50 \mathrm{~Hz}$ sinusoidal AC testing several low current settings-including 45, 60, and $75 \mathrm{~mA}$-currents below $75 \mathrm{~mA}$ failed to adequately stun birds after 4 to 5 s (Gregory \& Wotton, 1990). Using a $350 \mathrm{~Hz}$ pulsed DC applied for 4 s, Gregory and Wotton (1991) showed that only $40 \%$ of birds were adequately stunned when the current level fell below $120 \mathrm{~mA}$. Given that stunning efficacy decreases as frequency increases (Raj et al., 2006) and that a sine wave AC is more effective than pulsed DC with $50 \%$ duty cycle (Raj et al., 2006a), it is doubtful whether highfrequency pulsed DC with ultrabrief pulse width settings (i.e., less than $10 \%$ duty cycle) used in the United States would produce an effective stun immediately. In fact, Raj et al. (2006a) showed that using a pulsed DC with a 50\% duty cycle for $1 \mathrm{~s}$, electrical frequencies above $200 \mathrm{~Hz}$ (as commonly found in U.S. slaughter plants) would require an average current greater than $200 \mathrm{~mA}$ in order to immediately induce epileptiform activity in EEG recordings in a majority of birds (Raj et al., 2006a). This current is far greater than the 10-45 mA per bird often found in U.S. facilities. Clearly, more investigation is needed to reveal the effects of U.S. stunner settings on the spontaneous and evoked brain activities indicative of effective electrical stunning before such settings can be claimed to be effective or humane.

When passed through an electrical water-bath stunner, birds may show seizures, visually indistinguishable from effectively stunned birds, without the manifestation of epileptiform activity in the EEGs. As previously stated, effective electrical stunning induces epileptiform EEGs indicative of brain state incompatible with the persistence of consciousness and sensibility. However, the amount of current necessary to induce an epileptiform EEG is more than the amount necessary to induce seizures (Raj et al., 2006; Schütt-Abraham et al., 1983). In electrical water-bath stunning, current flows through both the head and body of the bird and induces tonic seizures. During a tonic seizure, the body of the bird stiffens as muscles contract, the neck is arched, the legs are rigidly extended, rhythmic breathing stops, the eyes are wide open, and the blink reflex is absent (EFSA, 2004b). At the end of tonic seizure, the muscles start to relax and the bird becomes limp for a short period. After this stage, rhythmic breathing starts and normal muscle tone returns gradually if the birds have not suffered cardiac arrest at the point of stunning (Gregory, 1986; Gregory \& Wotton, 1990; von Wenzlawowicz \& von Holleben, 2001). Ineffective electrical stunning also induces this sequence but without the epileptiform EEGs (Raj et al., 2006; Schütt-Abraham et al., 1983). Even the comb pinch response may be absent in these apparently stunned birds (SchüttAbraham et al., 1983). Observations of these outward physical signs have led to the suggestion that some electrically stunned birds may not be unconscious following attempts to stun them in an electrified water-bath but are rather in a state of electrically induced paralysis (Heath, Watt, Waite, \& Ormond, 1981; Schütt-Abraham et al., 1983). A mechanism for this possibility has been proposed in subsequent experimental work showing how variation in skull bone resistivity can cause deflection of the current path so that only a small portion of the applied current actually flows through the brain (Woolley, Borthwick, \& Gentle, 1986a, 1986b). Even when head-only electrical stunning is used, prolonged application of lowamperage currents may cause electrical immobilization and prevent animals from displaying outward signs of pain without rendering them unable to experience pain, stress, or discomfort (Croft, 1952). In view of the fact that both effectively stunned birds and ineffectively stunned birds exhibit tonic seizures and other outward signs such as lack of breathing and loss of muscle tone, it is more than likely that muscular paralysis, rather than unconsciousness and insensibility, is induced by prolonged application of inadequate current parameters. This induction of seizures in conscious birds would obviously cause pain and suffering, and these birds would remain sensible and able to feel pain during their subsequent slaughter and the throat-cutting step. 


\section{Missing the Stun-Bath}

Some birds are conveyed through the stunner without ever making complete contact with the electrified water-bath. Birds can miss the stunner if they flap their wings or struggle and lift their heads, if the height of the stunner is not correctly adjusted, or if birds are too short to reach the water-bath (Heath et al., 1981; Raj, 2004; Shane, 2005). End-of-lay hens (also known as "spent" hens) are especially prone to missing the stun-bath as they are more likely to struggle in the shackles (Van der Sluis, 2007; Webster, 2007). One of the major disease challenges facing poultry veterinarians in the United States is Runting Stunting Syndrome (RSS) of broiler chickens. RSS-affected flocks have poor growth and lack uniformity in size. This hinders "processability" (National Institute for Animal Agriculture, 2007, p. 2) and may worsen the problem of small birds missing the stunner. Indeed, birds who miss the stunner or make incomplete contact with the stunner may remain conscious or regain consciousness when their necks are cut. Although advances in electrical water-bath design, such as the installation of rump bars to limit movement and breast rub pads to calm birds, may help prevent birds from missing the stun-bath (Bilgili, 1999), smaller birds (particularly runts) may still reach the killing machine while fully conscious. Additionally, as RSS-affected birds would remain physically (and electrically) in contact with the adjacent birds passing through the stunner, the possibility that the RSS birds would receive painful electric shocks in a conscious state cannot be ruled out.

\section{Neck Cutting and Scalding}

Effectively stunned birds who have not undergone cardiac arrest at stunning must be killed quickly, otherwise they will regain consciousness (Gregory, 1986). The duration of unconsciousness induced by a stun depends on the amount and frequency of the current (Raj, 2003). Even if birds are adequately stunned, they may regain consciousness during bleed-out and enter the scald vat while alive if the neckcutting step is not performed quickly or if it is ineffective-if it fails to sever vessels supplying oxygenated blood to the brain. A ventral neck cut, which severs both carotid arteries, is more effective at inducing a rapid death than a neck cut that severs only one carotid artery (Gregory \& Wotton, 1986). Unlike the United States, ventral neck cutting is not always practiced in some countries. Even in the United States, severance of both the carotid arteries in the necks of different size birds may not always be possible when using neck-cutting machines, and it is not known how often birds miss the knife or blades. The killing machine is fixed at a specific height whereas the birds' heads may hang at different heights if there are any variations in bird size. Owing to this, the possibility that some birds would miss the blades could not be ruled out. In the United States, the United Kingdom, and other industrialized countries, plant personnel are usually present to manually cut the throat of birds who miss the automated knife, but line speeds can prevent backup personnel from detecting live birds exiting the killing machine with intact blood vessels. There is currently a lack of data demonstrating the effectiveness of this step in the process.

Some U.S. slaughter plants decapitate birds immediately after they exit the stunner, and such practices would obviously prevent a return to consciousness. However, the use of decapitation as a routine killing method raises further concerns on ethical grounds due to the large number of birds involved. At worst, decapitation of conscious bird does not produce immediate loss of consciousness and sensibility in the severed head as spontaneous and evoked activity in the brain can persist for several seconds (Gregory \& Wotton, 1986). It is also worth mentioning that cervical dislocation of poultry frequently leads to decapitation, and a proposed European Council Regulation stipulates that cervical dislocation "shall not be used on more than fifty animals per day" (Commission of the European Communities, 2008, Chapter II.2. Specific requirement for certain methods).

Occasionally, birds who did not receive an adequate stun, missed the killing machine, or recovered from the stun due to poor neck-cutting practices enter the scald tank alive and possibly conscious (Gregory, 1986; Heath et al., 1981; Heath, Watt, Waite, \& Meakins, 1983). The United States Department of Agriculture's records show that in 2008 more than 1.1 million chickens and turkeys were condemned as cadavers-a term used to describe carcasses of birds who died due to reasons other than slaughter (USDA, 2010). Some of these birds may have been alive when they entered the scald tank, and 
according to the Food Safety Inspection Service (FSIS), "when submerged in the hot water, they drown" (FSIS, 2005).

\section{Summary of Electrical Water-Bath Stunning}

Historically, the development of electrical stunning devices was driven more by the need to facilitate processing and automation of slaughter than by concern for bird welfare (Boyd, 1994). Although waterbath stunning could theoretically produce a state of insensibility rapidly, the complexities of ensuring the correct electrical settings and the conflict between effective stunning and commercial interests in carcass and meat quality largely preclude these conditions in practice. However, the welfare concerns of shackling conscious birds remain, even if electrical variables could be satisfactorily controlled. Questions about the nature of the state of unconsciousness (or lack thereof) actually produced by electrical waterbaths raises further concerns about the system. We are aware of no direct evidence demonstrating that the electrical settings used in the United States are adequate to meet international standards for humane stunning and slaughter of poultry. This absence of evidence has been misconstrued as evidence that existing methods are humane. In summary, the existing multiple-bird, electrical water-bath stunning systems supplied with constant voltages are inadequate on welfare grounds because they do not always ensure slaughter of birds with the minimum of pain and suffering possible.

\section{CONTROLLED ATMOSPHERE KILLING (CAK)}

CAK in transport crates or modules does not require live bird handling at the slaughter plants and thereby avoids the problems associated with dumping, handling, and shackling live birds, although the design of some gas systems requires that birds must still be dumped from their transport crates prior to entering the gas-filled chamber on a conveyer belt. Although such systems still retain many of the welfare advantages of CAK systems, those that move birds through the gaseous atmosphere while they are still in their transport crates are optimal. As well, these systems do not risk prestun shocks and/or ineffective stunning. In some CAK systems, birds in transport crates or modules are conveyed through a tunnel filled with increasing concentrations of carbon dioxide (CO2), inert gases (argon or nitrogen), or a mixture of these gases. The birds are exposed to lethal concentrations of gases long enough that they are actually killed rather than simply stunned (Raj, 1998), but the bleed-out process and carcass and meat quality are not negatively impacted (Raj \& Gregory, 1991; Raj, Grey, \& Gregory, 1990).

In contrast, with CAS, the potential exists for birds to regain consciousness after exiting the gaseous atmosphere while being shackled and conveyed to the neck cutter or during bleeding.

To obtain the full welfare benefits of the system, it is imperative that the birds are actually killed, rather than stunned, by the gas or gases. Some commercial processors continue to use the term "controlled atmosphere stunning" even when they have a CAK system in place for various reasons. For example, birds subjected to CAK show residual heart activity for a few minutes after the cessation of other functions such as breathing. Evidently, the use of terms CAK and CAS depends on how "death" is defined under this circumstance.

\section{Current Research on Gas Mixtures}

Some of the first research on the use of gas to stun birds was published in the 1950s (Kotula, Drewniak, \& Davis, 1957), and, by the late 1990s, continuing research led to the adoption of the first commercial gas stunning systems. In this regard, controlled atmosphere stunning/killing of poultry was legislated in the United Kingdom (Her Majesty's Stationery Office, 1995), for example. CO2, a by-product of the chemical and fertilizer industries, was initially examined in research studies for poultry slaughter plants because it is easily obtainable and relatively inexpensive. However, interest in the inert gases, including argon and nitrogen, was sparked by human aviation physiology studies, which demonstrated that anoxia-induced unconsciousness is euphoric (Ernsting, 1965). It was on the basis of this research that studies into the least aversive gas mixtures began (Gregory, 1987). 
Inhalation of the inert gases is thought to be painless because birds do not demonstrate aversive reactions with initial exposure. In behavior experiments, both turkeys and chickens willingly entered a chamber filled with argon in order to access food (Raj, 1996; Webster \& Fletcher, 2004). In contrast, physiological and behavioral evidence suggests that $\mathrm{CO} 2$ may be unpleasant and possibly very distressing to inhale as it is an acidic, pungent gas at high concentration Birds have intrapulmonary chemoreceptors that detect $\mathrm{CO} 2$ but are insensitive to the effects of hypoxia induced with argon and nitrogen (Ludders, 2001), which are both tasteless and odorless. Birds show signs of respiratory distress when exposed to $\mathrm{CO} 2$ and will often avoid an atmosphere containing high $\mathrm{CO} 2$ concentrations when tested in behavior experiments (Raj, 1996, 1998).

The primary concern with using inert gases to stun and kill birds is that these gases cause convulsions as the birds lose consciousness. Convulsions are thought to be reflexive reactions that occur only after the bird loses consciousness, but new research results contradict this theory, as discussed later. Further, the thrashing of one bird may frighten or physically harm, albeit briefly, other birds who have not yet lost consciousness. These convulsions can be aesthetically unpleasant to human observers and also involve powerful leg and wing movements (Webster \& Fletcher, 2004). Broken wing bones caused by convulsions can also reduce the quality of the carcass. For these reasons and because inert gases are not readily available in large quantities or are more expensive to obtain than $\mathrm{CO} 2$, the poultry industry has been reluctant to adopt CAK technology in the United States. In contrast, the United Kingdom has implemented legislative efforts to improve bird welfare; UK estimates show that more than $90 \%$ of turkeys and $25 \%$ of chickens slaughtered for human consumption are killed using inert mixtures (Anglia Autoflow Ltd., personal communication, n.d.).

As an alternative to inert gases, two-step systems that first render the birds unconscious with a low level of $\mathrm{CO} 2$ followed by a second stage with exposure to a lethal $\mathrm{CO} 2$ level are being adopted commercially, especially in Europe. Exposure to low concentrations of CO2, such as 30\% by volume in air, does not cause convulsions to the extent that inert gases do; despite its aversiveness, $\mathrm{CO} 2$ at low levels is thought to produce an anesthetic effect that reduces pain sensitivity for a variety of species (Andrews et al., 1993). The humaneness of exposure to low concentrations of CO2 has been evaluated, and it has been argued that $\mathrm{CO} 2$ levels of $30 \%$ or less may not be much more aversive to inhale than the inert gas argon. This was demonstrated initially by Webster and Fletcher (2004), who showed that nearly as many moderately food-deprived chickens would enter a feeding chamber and lose posture (an early sign of onset of unconsciousness) due to gas exposure when the chamber was filled with $30 \% \mathrm{CO} 2$ in air compared with argon. Similar results were subsequently reported in another study testing the aversiveness of several different gas mixtures (CO2 in air at concentrations ranging from 10 to $70 \%, \mathrm{CO} 2$ in nitrogen ranging from 25 to $40 \%$ with $30 \%$ oxygen, and 100\% argon and $100 \%$ nitrogen) by exposing broiler chickens to a 10-s pulse of gas while the birds fed. Based on the tendency of chickens to cease feeding during gas delivery over the feed dish, the authors concluded that low levels of $\mathrm{CO} 2$ are only mildly or moderately aversive (McKeegan, McIntyre, Demmers, Wathes, \& Jones, 2006).

In recent experiments using several different gas mixtures, McKeegan, Abeyesinghe, et al. (2007) concluded that a two-step system using $40 \% \mathrm{CO} 2,30 \% \mathrm{O} 2$, and $30 \% \mathrm{~N}$ in the first phase and $80 \% \mathrm{CO} 2$, $5 \% \mathrm{O} 2$, and $15 \% \mathrm{~N}$ in the second phase was best compared with a one-step system using either argon or argon mixed with $30 \%$ carbon dioxide from both a bird welfare and a meat quality perspective (Abeyesinghe et al., 2007; McKeegan, Abeyesinghe, et al., 2007). Not unexpectedly, behavioral observations at the slaughter plant showed that wing flapping and jumping associated with convulsions were greater in the gas mixture tested that contained argon, and this led to fractured wings and hemorrhages, whereas the transition to a motionless state was longer but occurred without convulsions while using the $40 \% \mathrm{CO} 2,30 \% \mathrm{O} 2$, and $30 \% \mathrm{~N}$ in the induction phase (McKeegan, Abeyesinghe, et al., 2007). A further concern was that parallel laboratory studies were not able to rule out the possibility that the initial vigorous behavioral response to the gas mixture containing argon occurred while chickens were still conscious (Coenen, Lankhaar, Lowe, \& McKeegan, 2009; McKeegan, McIntyre, et al., 2007). In contrast, Raj et al. (2008) provided EEG evidence to suggest that convulsions occurred in chickens only after the loss of consciousness, as ascertained from the occurrence of a profoundly suppressed EEG. However, further gas aversion studies confirmed previous evidence that birds find inert gases less aversive than CO2 greater than 30\% by volume (Sandilands, Raj, Baker, \& Sparks, 2006, 2008). 
The EEG analytical procedures used to determine the state of consciousness vary widely and are constantly evolving. Therefore, the debate about the persistence of consciousness at the time of onset of convulsions may continue until further research provides insight into or elucidates the brain mechanisms associated with convulsions and the state of consciousness. Nevertheless, this academic debate should not prevent the poultry industry from adopting CAK technology. Regardless of the gas mixture used, CAK eliminates the problems associated with handling and shackling conscious birds, painful prestun shocks, and variations in current that may or may not render birds unconscious and insensible without causing avoidable pain and suffering. Pending further research that will undoubtedly continue to refine and improve the knowledge and understanding of the procedure, many gas mixtures are currently being used, and all have bird welfare benefits when compared with the multiple bird, electrical water-bath stunning systems supplied with constant voltages.

\section{Additional Benefits of CAK}

In addition to the benefits associated with higher bird welfare at slaughter, CAK also improves the working conditions for people shackling conscious birds. Shackling is performed in near total darkness to help calm the birds and minimize the incidence of wing flapping (Ashdown, 1998; Occupational Safety and Health Administration [OSHA], 2005), to "facilitate grasping and hanging them" (Lee, Gogate, \& Carey, 1998, p. 3356), and to reduce injuries that can result in carcass downgrades (Sams, 2001). The inadequate lighting in this area of the slaughter facility contributes to a number of occupational hazards including cuts, slips, and falls (OSHA, 2005).

Many of the human health and safety risks created during shackling result from workers having to invert conscious birds and shackle them on the overhead conveyor. As workers attempt to shackle the birds by their feet, the birds may scratch and peck, and their flailing movements lead to high levels of dust, mites, and other airborne microorganisms in the live bird handling area (Ashdown, 1998). Sampling for airborne bacteria at various stages of turkey and duck slaughter found that "[a]irborne microbial counts in each plant were highest in shackling areas" (Lutgring, Linton, Zimmerman, Peugh, \& Heber, 1997, p. 804), which is likely due to the birds' feathers and "excessive bird movement, i.e., flapping of wings" (Lutgring et al., 1997, p. 806; see also Lues, Theron, Venter, \& Rasephei, 2007). According to OSHA, workers shackling live birds "get covered with poultry mess and dust that can expose them to diseases associated with handling live chickens and contact with poultry faeces and dust, such as allergic alveolitis, cryptosporidiosis, histoplasmosis, hypersensitivity pneumonitis, psittacosis, and Newcastle disease" (OSHA, 2005). These unhygienic and stressful working conditions put workers at risk of developing visual and respiratory ailments (Lee et al., 1998; Sams, 2001), allergic reactions, and respiratory infections (Lues et al., 2007). As well, if workers are cut or scratched by the struggling birds, their wounds can easily become infected in these unsanitary conditions (Lee et al., 1998).

According to the International Labour Organization's Encyclopaedia of Occupational Health and Safety, workers shackling live birds are also at risk of being sprayed by feces in the face (Ashdown, 1998). This concern is echoed by Human Rights Watch, which reports that birds may defecate on workers below as they hoist the birds up onto the hooks (Cobb, 2004).

CAK systems, in contrast, eliminate the live bird shackling step in the slaughter process. Operators do not handle the birds until they are unconscious or killed with gas mixtures, which eliminates the difficulty of handling live and struggling birds, reduces aerial dust and dander, and allows the job to be performed under brighter lighting conditions (Gazdziak, 2007). The benefits to workers can be greater in turkey slaughter plants, especially those slaughtering heavy turkeys.

\section{CONCLUSION}

There are serious problems associated with multiple-bird, electrical water-bath stunning systems. Research evidence suggests that electrical parameters as practiced in the United States do not guarantee an adequate stun. Indeed, the existing U.S. standards do not even conform to the minimum standards recommended in the guidelines of the OIE (2008b). Legislating minimum currents, however, 
would not overcome the other inherent welfare problems associated with the electrical water-bath stunning system. Therefore, it is not surprising that the Scientific Panel on Animal Health and Welfare, in its opinion on request from the European Commission, stated, "Since welfare is poor when the shackling line and water bath electrical stunning method is used, and birds are occasionally not stunned before slaughter, the method should be replaced as soon as possible" (EFSA, 2004a, p. 16).

Indeed, it is ethically imperative that slaughter be effective, quick, and painless_particularly in countries such as the United States, where birds killed for food are not afforded legal protections to ensure their welfare at slaughter. As international governing bodies for animal health and welfare have concluded (EFSA, 2004a; OIE, 2008b), CAK is the method that most closely reaches the ideal conditions for slaughtering birds with a minimum of avoidable pain and suffering. Further benefits, including better working conditions for live bird shackling operators and reports of improved carcass quality (Kingsbury, 2007), solidify that this technology is strongly preferred to the existing multiple-bird, electrical water-bath stunning systems supplied with constant voltages. Wider implementation of CAK technologies would greatly improve the welfare of both birds and processing plant employees in the United States and globally.

\section{REFERENCES}

Abeyesinghe, S. M., McKeegan, D. E. F., McLeman,M. A., Lowe, J. C., Demmers, T. G. M., White, R. P., ... Wathes, C. M. (2007). Controlled atmosphere stunning of broiler chickens: I. Effects on behaviour, physiology and meat quality in a pilot scale system at a processing plant. British Poultry Science, 48, 406-423.

Andrews, E., Bennett, B. T., Clark, J. D., Houpt, K. A., Pascoe, P. J., Robinson, G. W., \& Boyce, J. R. (1993). Report of the AVMA panel on euthanasia. Journal of the American Veterinary Medical Association, 202, 229-249.

Animal Agriculture Alliance. (n.d.). Statement by the Animal Agriculture Alliance Coalition: Agriculture's commitments to animal well-being. Retrieved from http://www.animalagalliance.org/images/ ag_insert/Pew/Animal_Welfare.pdf

Ashdown, T. (1998). Poultry processing. In J. M. Stellman (Ed.), International Labour Organization encyclopaedia of occupational health and safety (4th ed., pp. 67.17-67.22). Geneva, Switzerland: International Labour Organization.

Bedanova, I., Voslarova, E., Chloupek, P., Pistekova, V., Suchy, P., Blahova, J., ... Vecerek, V. (2007). Stress in broilers resulting from shackling. Poultry Science, 86, 1065-1069.

Bilgili, S. F. (1992). Electrical stunning of broilers-basic concepts and carcass quality implications: A review. Journal of Applied Poultry Research, 1(1), 135-146.

Bilgili, S. F. (1999). Recent advances in electrical stunning. Poultry Science, 78, 282-286.

Boyd, F. (1994). Humane slaughter of poultry: The case against the use of electrical stunning devices. Journal of Agricultural \& Environmental Ethics, 7, 221-236.

Cobb, R. (2004). The chicken hangers: INTHEFRAY. Retrieved from http://www.thelaborers.net/NEWS/poultry_workers/default.htm

Coenen, A. M. L., Lankhaar, J., Lowe, J. C., \& McKeegan, D. E. F. (2009). Remote monitoring of electroencephalogram, electrocardiogram, and behavior during controlled atmosphere stunning in broilers: Implications for welfare. Poultry Science, 88, 10-19.

Commission of the European Communities. (2008). Proposal for a council regulation on the protection of animals at the time of killing. Retrieved from http://ec.europa.eu/food/animal/welfare/slaughter/proposal_en.pdf

Craig, E. W., \& Fletcher, D. L. (1997). A comparison of high current and low voltage electrical stunning systems on broiler breast rigor development and meat quality. Poultry Science, 76, 1178-1181.

Croft, P. S. (1952). Problems of electrical stunning. The Veterinary Record, 64, 255-258.

Danbury, T. C., Weeks, C. A., Chambers, J. P., Waterman-Pearson, A. E., \& Kestin, S. C. (2000). Selfselection of the analgesic drug carprofen by lame broiler chickens. The Veterinary Record, 146, 307-311. 
Debut, M., Berri, C., Arnould, C., Guemené, D., Santé-Lhoutellier, V., Sellier, N., : : : Le Bihan-Duval, E. (2005). Behavioural and physiological responses of three chicken breeds to pre-slaughter shackling and acute heat stress. British Poultry Science, 46, 527-535.

Ernsting, J. (1965). The effect of anoxia on the central nervous system. In J. A. Gillies (Ed.), A text book of aviation physiology (pp. 271-289). Oxford, UK: Pergamon.

European Food Safety Authority. (2004a). Opinion of the Scientific Panel on Animal Health and Welfare on a request from the commission related to welfare aspects of the main systems of stunning and killing the main commercial species of animals. The EFSA Journal, 45, 1-29.

European Food Safety Authority. (2004b). Scientific report of the Scientific Panel on Animal Health and Welfare on a request from the commission related to welfare aspects of animal stunning and killing methods (pp. 125-126). Retrieved http://www.efsa.europa.eu/cs/BlobServer/Scientific_Opinion/opinion_ahaw_02_ej45_stunning_re port_v2_en1,1.pdf?ssbinaryDtrue

Food and Agriculture Organization of the United Nations. (2008). FAO-STAT. Retrieved from http://faostat.fao.org/site/569/DesktopDefault.aspx?PageIDD569\#ancor

Food Safety Inspection Service. (2005). Slaughter inspection training. Poultry postmortem inspection ( $p$. 15). Retrieved from http://www.fsis.usda.gov/PDF/PSIT_PostMortem.pdf

Gazdziak, S. (2007, December). Kill floor improvements: Automation on the poultry kill and eviscerating lines is increasing efficiency and product quality. The National Provisioner, pp. 66-68.

Gentle, M. J. (1992). Ankle joint (artc. intertarsalis) receptors in the domestic fowl. Neuroscience, 49, 991-1000.

Gentle, M. J., \& Tilston, V. L. (2000). Nociceptors in the legs of poultry: Implications for potential pain in pre-slaughter shackling. Animal Welfare, 9, 227-236.

Goldie, L., \& Green, J. M. (1961). Spike and wave discharges and alteration of conscious awareness. Nature, 191, 200-201.

Gregory, N. G. (1986). The physiology of electrical stunning and slaughter. In Proceedings of a symposium at the Zoological Society of London (pp. 3-14). Hertfordshire, UK: Universities Federation for Animal Welfare.

Gregory,N. G. (1987). Determination of impaired brain function in animals in the laboratory. In Preslaughter stunning of food animals (pp. 2-16). Brussels, Belgium: European Conference Group on the Protection of Farm Animals.

Gregory, N. G. (1994). Pathology and handling of poultry at the slaughterhouse. World's Poultry Science Journal, 50, 66-67.

Gregory, N. G., Austin, S. D., \& Wilkins, L. J. (1989). Relationship between wing flapping at shackling and red wingtips in chicken carcasses. The Veterinary Record, 124, 62.

Gregory, N. G., \& Bell, J. C. (1987).Duration of wing flapping in chickens shackled before slaughter. The Veterinary Record, 121, 567-569.

Gregory, N. G., \& Wotton, S. B. (1986). Effect of slaughter on the spontaneous and evoked activity of the brain. British Poultry Science, 27, 195-205.

Gregory, N. G., \& Wotton, S. B. (1987). Effect of electrical stunning on the electroencephalogram in chickens. British Veterinary Journal, 143, 175-183.

Gregory, N. G., \& Wotton, S. B. (1990). Effect of stunning on spontaneous physical activity and evoked activity in the brain. British Poultry Science, 31, 215-220.

Gregory, N. G., \& Wotton, S. B. (1991). Effect of a $350 \mathrm{~Hz}$ DC stunning current on evoked responses in the chicken's brain. Research in Veterinary Science, 50, 250-251.

Heath, G. B., Watt, D. J., Waite, P. R., \& Meakins, P. A. (1983). Further observations on the slaughter of poultry. British Veterinary Journal, 139, 285-290.

Heath, G. B., Watt, D. J., Waite, P. R., \& Ormond, J. M. (1981). Observations on poultry slaughter. The Veterinary Record, 108, 97-99.

Her Majesty's Stationery Office. (1995). The welfare of animals (slaughter or killing) regulations, Statutory Instrument No. 731.

Kannan, G., Heath, J. L., Wabeck, C. J., \& Mench, J. A. (1997). Shackling of broilers: Effects on stress responses and breast meat quality. British Poultry Science, 38, 323-332.

Kannan, G., \& Mench, J. A. (1996). Influence of different handling methods and crating periods on plasma corticosterone concentrations in broilers. British Poultry Science, 37, 21-31. 
Kettlewell, P. J., \& Hallworth, R. N. (1990). Electrical stunning of chickens. Journal of Agricultural Engineering Research, 47, 139-151.

Kingsbury, A. (2007, August). Controlled atmospheric stunning: ACA co-operative installs North America's first system for broilers. Canadian Poultry Magazine, pp. 28-30.

Kotula, A. W., Drewniak, E. E., \& Davis, L. L. (1957). Effect of carbon dioxide immobilization on the bleeding of chickens. Poultry Science, 36, 585-589.

Lambooij, E., Pieterse, C., Hillebrand, S. J. W., \& Dijksterhuis, G. B. (1999). The effects of captive bolt and electrical stunning, and restraining methods on broiler meat quality. Poultry Science, 78, 600-607.

Lee, K. M., Gogate, R., \& Carey, R. (1998). Automated singulating system for transfer of live broilers. In Proceedings of the 1998 Institute of Electrical and Electronics Engineers (IEEE) International Conference on Robotics and Automation (pp. 3356-3361). Leuven, Belgium.

Ludders, J. W. (2001). Inhaled anaesthesia for birds. In R. D. Gleed \& J. W. Ludders (Eds.), Recent advances in veterinary anesthesia and analgesia: Companion animals. Ithaca, NY: International Veterinary Information Service.

Lues, J. F. R., Theron, M. M., Venter, O., \& Rasephei, M. H. R. (2007). Microbial composition in bioaerosols of a high throughput chicken-slaughtering facility. Poultry Science, 86, 142-149.

Lutgring, K. R., Linton, R. H., Zimmerman, N. J., Peugh, M., \& Heber, A. J. (1997). Distribution and quantification of bioaerosols in poultry-slaughtering plants. Journal of Food Protection, 60, 804810.

McKeegan, D. E., Abeyesinghe, S. M., McLeman, M. A., Lowe, J. C., Demmers, T. G. M., White, R. P., ... Wathes, C. M. (2007). Controlled atmosphere stunning of broiler chickens: II. Effects on behaviour, physiology and meat quality in a commercial processing plant. British Poultry Science, 48, 430-442.

McKeegan, D. E. F., McIntyre, J. A., Demmers, T. G. M., Lowe, J. C., Wathes, C. M., van den Broek, P. L. C., : : : Gentle, M. J. (2007). Physiological and behavioural responses of broilers to controlled atmosphere stunning: Implications for welfare. Animal Welfare, 16, 409-426.

McKeegan, D. E. F., Mclntyre, J., Demmers, T. G. M., Wathes, C. M., \& Jones, R. B. (2006). Behavioural responses of broiler chickens during acute exposure to gaseous stimulation. Applied Animal Behaviour Science, 99, 271-286.

National Institute for Animal Agriculture (NIAA). (2007, Fall/Winter). U.S. broiler health shows slight decline. Poultry Health Report, p. 2.

Nunes, F. (2007). How to avoid bruising during electrical poultry stunning. Retrieved from http://Meatingplace.com

Occupational Safety and Health Administration. (2005). Receiving and killing-task 3: Live hang. Poultry processing industry eTool. U.S. Department of Labor. Retrieved from http://www.osha.gov/SLTC/etools/poultry/receiving/03_live_hang.html

Office International des Épizooties. (2008a). Second OIE Global Conference on Animal Welfare (pp. 2022). Retrieved from http://www.oie.int/eng/A_AW2008/ANG_Final\%20Recommendations.pdf

Office International des Épizooties. (2008b). Terrestrial Animal Health Code 2007. Section 3.7.5. Guidelines for the slaughter of animals. World Organisation for Animal Health. Retrieved from http://www.oie.int/eng/normes/mcode/en_chapitre_3.7.5.htm

Porter, R. J., \& Penry, J. K. 1973. Responsiveness at the onset of spike-wave bursts. Electroencephalography and Clinical Neurophysiology, 34, 239-245.

Raj, A. B. M. (1996). Aversive reactions of turkeys to argon, carbon dioxide and a mixture of carbon dioxide and argon. The Veterinary Record, 138, 592-593.

Raj, A. B. M. (1998). Welfare during stunning and slaughter of poultry. Poultry Science, 77, 1815-1819.

Raj, A. B. M. (2003). A critical appraisal of electrical stunning in chickens. World's Poultry Science Journal, 59(1), 89-98.

Raj, A. B. M. (2004). Stunning and slaughter of poultry. In G. C. Mead (Ed.), Poultry meat processing and quality. Cambridge, UK: Woodhead.

Raj, A. B. M., \& Gregory, N. G. (1991). Efficiency of bleeding of broilers after gaseous or electrical stunning. Veterinary Record, 128, 127-128.

Raj, A. B. M., Grey, T. C., \& Gregory, N. G. (1990). Effect of electrical and gaseous stunning on the carcass and meat quality of broilers. British Poultry Science, 31, 725-733. 
Raj, A. B. M., O'Callaghan, M., \& Hughes, S. I. (2006a). The effects of amount and frequency of pulsed direct current used in water bath stunning and of slaughter methods on spontaneous electroencephalograms in broilers. Animal Welfare, 15, 19-24.

Raj, A. B. M., O'Callaghan, M., \& Hughes, S. I. (2006b). The effects of pulse width of a direct current used in water bath stunning and of slaughter methods on spontaneous electroencephalograms in broilers. Animal Welfare, 15, 25-30.

Raj, A. B. M., O'Callaghan, M., \& Knowles, T. G. (2006). The effects of amount and frequency of alternating current used in water bath stunning and of slaughter methods on electroencephalograms in broilers. Animal Welfare, 15, 7-18.

Raj, A. B. M., O'Callaghan, M. C., Thompson, K., Becket, D., Morrish, I., Love, A., ... Howson, S. (2008). Large-scale killing of poultry species on farm during outbreaks of diseases: Evaluation and development of a humane containerised gas killing system. World's Poultry Science Journal, 64, 227-243.

Sams, A. R. (2001). First processing: Slaughter through chilling. In A. R. Sams (Ed.), Poultry meat processing (p. 21). Washington, DC: CRC.

Sandilands, V., Raj, A. B. M., Baker, L., \& Sparks, N. H. C. (2006). Aversion of chickens to various gases: Methods for humane culling. In M. Mendl, J. W. S. Bradshaw, O. H. P. Burman, A. Butterworth, M. J. Harris, S. D. E. Held, ... P. D. Warris (Eds.), Proceedings of the $40^{\text {th }}$ International Congress of the International Society for Applied Ethology (p. 64). Bristol, UK: ISAE Scientific Committee.

Sandilands, V., Raj, A. B. M., Baker, L., \& Sparks, N. H. C. (2008). Humane culling of poultry during a disease outbreak: Aversion to various gas mixtures. British Poultry Abstracts, 4, 22-23.

Satterlee, D. G., Parker, L. H., Castille, S. A., Cadd, G. G., \& Jones, R. B. (2000). Struggling behavior in shackled male and female broiler chickens. Poultry Science, 79, 652-655.

Schütt-Abraham, I., Wormuth, H. J., \& Fessel, J. (1983). Electrical stunning of poultry in view of animal welfare and meat production. In G. Eikelenboom (Ed.), Stunning of animals for slaughter (pp. 187-196). The Hague, The Netherlands: Martinus Nijhoff.

Shane, S. (2005). Future of gas stunning. WATT Poultry USA, 6(4), 16-23.

Sparrey, J. M., \& Kettlewell, P. J. (1994). Shackling of poultry: Is it a welfare problem? World's Poultry Science Journal, 50, 167-176.

Sparrey, J. M., Kettlewell, P. J., Paice, M. E. R., \& Whetlor,W. C. (1993). Development of a constant current water bath stunner for poultry processing. Journal of Agricultural Engineering Research, $56,267-274$.

Tyson, J. (n.d.). Live production animal well-being: Our mission statement on animal well-being. Retrieved from http://www.tyson.com/Corporate/AboutTyson/LiveProduction/AnimalWellBeing.aspx

U.S. Department of Agriculture. (2010). Poultry slaughter: 2009 annual summary. National Agricultural Statistics Service. Retrieved from http://usda.mannlib.cornell.edu/usda/current/PoulSlauSu/PoulSlauSu-02-25-2010.pdf

Van der Sluis, W. (2007). Gas stunning reduces rejects in spent hen processing.World Poultry, 23(9), 3031.

von Wenzlawowicz, M., \& von Holleben, K. (2001). Assessment of stunning effectiveness according to the present scientific knowledge on electrical stunning of poultry in a waterbath. Archiv für Geflügelkunde, 65, 193-198.

Webster, A. B. (2007). The commercial egg industry should consider controlled atmosphere stunning for spent hens. The Poultry Site. Retrieved from http://www.thepoultrysite.com/articles/864/thecommercial-egg-industry-should-consider-ontrolledatmosphere-stunning-for-spent-hens

Webster, A. B., \& Fletcher, D. L. (2004). Assessment of the aversion of hens to different gas atmospheres using an approach-avoidance test. Applied Animal Behaviour Science, 88, 275-287.

Wilkins, L. J., Wotton, S. B., Parkman, I. D., Kettlewell, P. J., \& Griffiths, P. (1999). Constant current stunning effects on bird welfare and carcass quality. Journal of Applied Poultry Research, 8, 465471.

Woolley, S. C., Borthwick, F. J. W., \& Gentle M. J. (1986a). Flow routes of electric currents in domestic hens during pre-slaughter stunning. British Poultry Science, 27, 403-408.

Woolley, S. C., Borthwick, F. J.W., \& Gentle M. J. (1986b). Tissue resistivities and current pathways and their importance in pre-slaughter stunning of chickens. British Poultry Science, 27, 301-306. 
Wooton [sic for Wotton], S. B., \& Gregory, N. G. (1991). How to prevent pre-stun electric shocks in waterbath stunners. Turkeys, 39(2), 15, 30. 